\title{
In-Class Cyberloafing among Undergraduate Students of Physical Education and Sports Teaching Department
}

\author{
Orhan Çınar ${ }^{1}$, Zübeyr Cinisli ${ }^{2}$
}

\begin{abstract}
${ }^{1}$ Atatürk University, orhanar@gmail.com
\end{abstract}
${ }^{2}$ Atatürk University, zcinisli@atauni.edu.tr

Received: 30.12 .2017

Accepted: 24.01.2018

Online Published: 08.03.2018

doi: 10.30655/besad.2018.3

\begin{abstract}
In this study, the level of cyberloafing of the students enrolled in Physical Education and Sports Teaching Department was investigated. The main purpose of this research was to determine the students' cyberloafing behaviors during the lesson, to compare these behaviors according to the demographic characteristics of the students, and to make suggestions about how to take measures against this issue. "Cyberloafing Scale" was used to gather data. The Cronbach Alpha Coefficient of the scale was 0,87. The population of the study was comprised of the students enrolled in the Physical Education and Sports Teaching Department of Atatürk University. The sample consisted of 112 students who responded the questionnaires thoroughly. The data were analyzed using SPPS package program. When we ranked students' cyberloafing behaviors, instant messaging was at the top, visiting web sites with sports context was the in second place, and talking by phone was in third place. The level of cyberloafing behaviors of the students was found as moderate. Female students downloaded more files (e.g., music, software, video) and shop online more than male students.
\end{abstract}

Keywords: Cyberloafing, Physical Education and Sports Teaching,

\section{Beden Eğitimi ve Spor Öğretmenliği Bölümü Öğrencilerinin Siber Aylaklık Davranışları}

Öz

Bu çalışmada Beden Eğitimi ve Spor Öğretmenliği Bölümü öğrencilerinin siber aylaklık düzeyleri araştırılmaktadır. Öğrencilerin ders esnasında daha çok hangi siber aylaklık davranışlarını gösterdiklerinin belirlenmesi, bu davranışların ögrencilerin demografik özelliklerine göre farklılaşma durumunun tespit edilmesi ve buna karşı nasıl tedbirler alınacağı hususunda önerilerde bulunulması bu araştırmanın temel amacını oluşturmaktadır. Veri toplama aracı olarak "Siber Aylaklık Ölçeği" kullanılmıştır. Ölçeğin Cronbach Alpha Katsayısı 0,87 olarak elde edilmiştir. Araştırmanın çalışma evreni Atatürk Üniversitesi Spor Bilimleri Fakültesi Beden Eğitimi ve Spor Öğretmenliği Bölümü öğrencileridir. Araştırmanın örneklemi ise anketleri eksiksiz dolduran 112 ögrencidir. Veriler SPSS paket programı ile istatistiksel analize tabi tutulmuştur. Öğrencilerin siber aylaklık davranışları sıralamasının başında anlık mesajlaşma gelmektedir. İkinci sırada spor içerikli sitelerin ziyareti ve üçüncü sırada telefonla konuşma gelmektedir. Öğrencilerin siber aylaklı davranışı düzeyi orta olarak bulunmuştur. Demografik özelliklere göre yapılan karşılaştırmalara göre kız ögrenciler internet üzerinden daha fazla dosya (müzik, yazılım, video gibi) indirmekte ve daha fazla alışveriş yapmaktadirlar.

Anahtar Kelimeler: Siber Aylaklık, Beden Eğitimi ve Spor Öğretmenliği 


\section{Giriş}

Devamsızlık, kişilerin bulunması gereken; okul, işyeri, toplantı vb. yerlerde bulunmaması durumu olarak tanımlanabilir. Okula devamsızlık, çeşitli sebeplerden dolayı ortaya çıkan ve öğrenci akademik başarısını olumsuz yönde etkileyebileceği düşünülen istenmeyen bir öğrenci davranışıdır. Ancak fiziksel olarak sınıfa/okula geldiği, derste yer aldığı halde eğitim öğretim faaliyetlerine olması gerektiği gibi katılmamak, ilgi göstermemek, dikkatini vermemek, başka şeylerle uğraşmak da bir çeşit devamsızlık sayılabilir. Derse odaklanmayıp, öğrenme görevleri dışında başka şeyler yapmanın çeşitli sebepleri olabilir. Günümüzde öğrencileri ders esnasında dersten uzaklaştıran olumsuz davranışlardan biri siber aylaklıktır. Bazı kaynaklarda sanal kaytarma olarak da isimlendirilen bu davranış öğrenci akademik başarısını düşürdüğü gibi sınıf yönetimini de zorlaştırabilmektedir.

$\mathrm{Bu}$ çalışmada Atatürk Üniversitesi Spor Bilimleri Fakültesi Beden Eğitimi ve Spor Öğretmenliği Bölümü öğrencilerinin siber aylaklık düzeyleri araştırılmaktadır. Öğrencilerin ders esnasında daha çok hangi siber aylaklık davranışlarını gösterdiklerinin belirlenmesi, bu davranışların öğrencilerin demografik özelliklerine göre farklılaşma durumunun tespit edilmesi ve buna karşı nasıl tedbirler alınacağı hususunda önerilerde bulunulması bu araştırmanın temel amacını oluşturmaktadır.

\section{Kuramsal Çerçeve}

Bilgi ve iletişim teknolojileri günlük hayatta olduğu kadar, çalışma ve eğitim hayatında masaüstü/dizüstü bilgisayarlar, tabletler, mobil telefonlar (akıllı telefonlar) gibi araçların kullanılması yoluyla, bireylerin iş/öğrenme görevlerini yerine getirmesi ve kişisel ihtiyaçlarını karşılaması için vazgeçilmez bir unsur haline gelmiştir.

Bilişim teknolojisinin sağlamış olduğu avantajlar zamanla eğitim sektörünü de cezbetmiş, gerek idari işlerin yerine getirilmesinde gerek eğitim ve öğretim sürecinde bilgisayar ve internet yoğun bir şekilde kullanılmaya başlanmıştır.

Kablosuz internet bağlantısının eğitim kurumlarında yaygınlaşması, üniversite öğrencilerine uygulamalı bilgisayar teknolojileri dersinin verilmesi, hemen her kurumda olduğu gibi eğitimde de bilgi teknolojilerinin kullanılması, e-devlet uygulamalarının hayatımıza girmesi, bireylerin şahsi akıllı telefon veya kişisel bilgisayarını eğitim ortamında kullanması vb. gelişmeler eğitim ortamını oldukça değiştirmiştir. Bilişim teknolojilerinin amaç dışı kullanımı, yani alan yazındaki tabiri ile siber aylaklık davranışlar, iş ortamında olduğu gibi eğitim ortamında da etkisini göstermektedir. 
Siber aylaklığın örgüt için zararları ve yararları konusunda iki farklı yaklaşım söz konusudur. Bazı araştırmacılar, siber aylaklığın örgütler için son derece zararlı ve verimlilik kayıplarına neden olan bir olgu olduğunu ileri sürerken, diğerleri ise siber aylaklık sayesinde elde edilen eşsiz öğrenme firsatlarına vurgu yapmaktadır (Örücü ve Yıldız, 2014: 10). İşletmelerde olduğu gibi eğitim ve öğretim alanında da siber aylaklığın olumlu ve olumsuz sonuçlarının olduğu ifade edilmektedir.

Kişisel bilgisayar ya da kablosuz ağ bağlantılı elektronik cihazlara sahip (akıllı telefon, tablet, dizüstü bilgisayar gibi) olan üniversite öğrencilerinin büyük bir kısmının, öğrenmede daha fazla yol aldığı bildirilmiştir (Jones, 2002). Benzer şekilde, taşınabilir bilgisayarların öğrenci kariyeri için de yararlı olabileceği belirtilmiştir. Dizüstü bilgisayarı olan öğrencilerin bilgisayarlarını kullanabileceği sınıfları tercih ettiği ve bu yolla daha kolay öğrenmenin gerçekleşeceği de ifade edilmiştir. Buna ek olarak öğrencilerin kullandıkları kişisel bilgisayarlarının öğrenmede önemli bir araç olduğu söylenmektedir (Yıldırım, 2016)

Ancak eğitim ortamlarında dizüstü bilgisayar/akıllı telefon kullanımı ve öğrencilere sunulan kablosuz internet kullanma imkânı, öğrencilerin ders dışı davranışlar sergilemesine de neden olmaktadır. Bir başka deyişle, öğrenciler sorumlu oldukları öğrenme görevleri yerine (internet kullanımına dayalı) kendi özel görevlerini yerine getiriyor (siber aylaklık) ise bu durumda öğrenme etkileşimleri gerçekleşmemekte ve/veya eksik öğrenmeler söz konusu olmaktadır ki bu durum, dersin etkililiğini ve verimliliğini düşürmektedir.

Okullardaki bilgisayarlar ve özellikle internet bağlantısının sınıfa girmesiyle siber aylaklık davranışlarının öğrenciler tarafından gösterildiği gözlemlenmektedir. Özellikle mobil araçların yaygınlaşmasıyla siber aylaklık kavramı eğitim ortamlarında önemli bir sorun haline gelmiştir.

Siber aylaklık öğrencinin dikkatini derse odaklamasını zorlaştırdığından öğrenme performansını olumsuz etkileyen bir faktördür. Bunun yanında bu tür davranışlar, öğretmenin sınıf yönetimini zorlaştırmaktadır. Siber aylaklık en genel tanımıyla, örgütlerin sağlamış olduğu bilgisayar ve internetin kişisel amaçlar doğrultusunda kullanılmasıdır. Bu kullanım yabancı alan yazında "Cyberloafing”, "Cyberslacking”, "Cyberdeviance”, "Personel Web Usage” gibi terimler ile ifade edilmektedir (Lim, 2002; Ugrin, ve diğg. 2008; Anandarajan, ve diğ. 2004; Weatherbee ve Kelloway, 2006). Türkçe alan yazında "Sanal Kaytarma”, "Siber Aylaklık” gibi terimler kullanılmaktadır (Örücü ve Yıldız, 2014; Kurt, 2011). Eğitim alanındaki siber aylaklık ise bu terimlerin bir uyarlamasıdır. Knight (2017), yapmış olduğu çalışmada akademik siber aylaklık (academic cyberloafing) terimini kullanmıştır. 
"Sanal Aylaklık/Kaytarma (Student Cyberloafing), ders esnasında akademik amaçlar dişında mobil telefon ya da dizüstü bilgisayar kullanımını içeren davranışlardır (Knight, 2017). Alanyazın incelendiğinde, eğitim alanında siber aylaklık davranışları ile ilgili Türkiye'deki ilk tanımın Kalaycı (2010) tarafından yapıldı̆̆ı görülmektedir. Bu tanıma göre eğitimde siber aylaklık, öğrencilerin, ders saatleri içerisinde, interneti ders ile ilgisi olmayan işler için kullanma eğilimi ve/veya davranışıdır. Örneğin, bilgisayar laboratuvarında işlenen bilgisayar dersinde öğretmen Excel'de bir grafiğin nasıl çizileceğini anlatırken, öğrencinin önünde açık duran internette spor haberlerini okumas1, oyun oynaması, e-postalarını kontrol etmesi ya da öğrencinin ders esnasında akıllı telefonu ile herhangi bir sosyal medya hesabını kontrol etmesi siber aylaklık olarak tanımlanabilir.

Ergün ve Altun (2012) yaptıkları çalışmada siber aylaklık davranışının nedenlerini 5 tema altında açıklamışlardır: Motivasyon, ortam, öğretmen, derse hedeflenme ve zaman. Öğrenciler, motivasyon eksikliğinden dolayı ders esnasında internette başka etkinliklerle uğraşabilirler. Eğitim verilen ortamın sıcak ya da soğuk oluşu, sınıfın sşık seviyesi ve oturma düzeni gibi faktörler öğrencilerin siber aylaklık yapma eğilimlerini artırabilir. Siber aylaklık öğretmenden de kaynaklanabilir. Dersin monotonluğu, sınıf kuralların olmaması gibi faktörler siber aylaklık davranışı gösterilmesine sebep olabilir. Ayrıca hem ders içeriğinin kendilerine faydasının olup olmayacağı konusundaki tereddütleri hem de işlenen dersin süresi, öğrencileri siber aylaklık yapmaya yönlendiren diğer hususlardır.

Siber aylaklığın nedenlerinden birinin bilişsel kapılma olduğu da söylenmektedir. Bilişsel kapılma, teknoloji ile ilgili deneyimlerde yaşanan derin bağlılık durumu olarak tanımlanmaktadır (Agarwal ve Karahanna 2000; Koçak-Usluel ve Vural, 2009). Teknolojilerin bireyi cezbederek duygusal bir bağlanma oluşturduğu pek çok çalışmada gösterilmiştir.

\section{Yöntem}

$\mathrm{Bu}$ araştırmada genel tarama yöntemi kullanılmıştır. Genel tarama yöntemi, çok sayıda elemandan oluşan bir evrende, evren hakkında genel bir yargıya ulaşmak amacı ile evrenin tamamı veya ondan alınacak örnek veya örneklem üzerinde yapılan tarama düzenlemeleridir (Karasar, 2000: 79).

Araştırmanın çalışma evreni 2017 yılı Mayıs ayında Atatürk Üniversitesi Spor Bilimleri Fakültesi Beden Eğitimi ve Spor Öğretmenliği Bölümünde okuyan öğrencilerdir. Veriler anket tekniği kullanılarak elde edilmiştir. Araştırmanın örneklemi ise anketleri eksiksiz dolduran 112 öğrencidir. Öğrencilerin anket formalarını doğru ve içtenlikle cevapladıkları varsayılmıştır. 
Veri toplama aracı olarak Kalaycı (2010)'nın Blanchard and Henle (2008)'den Türkçeye uyarladığı "Siber Aylaklık Ölçeğì" maddeleri (13 madde) ile günümüz koşulları dikkate alınarak tarafımızdan eklenen 4 madde kullanılmıştır. Ölçek maddeleri, 5'li Likert şeklinde cevaplandırılmaktadır (1-Hiçbir zaman, 2-Nadiren, 3-Arasıra, 4-Sıklıkla, 5-Her zaman). Kalaycı (2010)'nın ölçeği uyarladığı tarihte henüz kullanımda olmayan bazı akıllı telefon ve bilgisayar uygulamaları günümüzde oldukça yaygın bir şekilde hayatımıza girmiştir. $\mathrm{Bu}$ noktadan hareketle bugünün şartları dikkate alınarak tarafımızdan 4 madde ölçeğe eklenmiştir. $\mathrm{Bu}$ maddeler, Tablo 3'te belirtilmiştir. $\mathrm{Bu}$ çalışmada ölçek maddeleri tek tek değerlendirildiğinden ölçeğe madde eklenmesinin ölçeği geliştirdiği ve güncellediğini kabul etmekteyiz. 17 maddeden oluşan ölçeğin Cronbach Alpha Katsayısı örneklemimiz için 0,87 olarak elde edilmiştir.

Beşli Likert biçiminde hazırlanan ölçek maddelerine verilen cevap kodları 1,00 ile 5,00 arasında değişmektedir. Aralıkların eşit olduğu varsayımından hareket edilerek, ortalamaları değerlendirmek için puan aralığı katsayısı 0,80 olarak bulunmuştur. Puan Aralığı Katsayısı = (En Yüksek Değer-En Düşük Değer) $/ 5=(5-1) / 5=4 / 5=0.80$. Buna göre ölçek maddelerinin ortalamaları şu şekilde değerlendirilmiştir: 1,00-1,80 Çok az; 1,81- 2.60 Az; 2,61-3,40 Orta; 3,41-4,20 Yüksek; 4,21-5.0 Çok yüksek (Çınar, 2010).

Veriler, SPSS Windows 16.0 programı ile bilgisayar ortamına aktarılmış, istatistiksel analizlerde frekans/yüzde dağılımları, ortalama, standart sapma, $\mathrm{t}$ testi ve varyans analizi kullanılmıştır.

\section{Bulgular}

Araştırmaya katılan öğrencilerin \%36'sı (40 kişi) kız, \%64'ü (72 kişi) erkektir.

Öğrencilerin kendi mobil hatlarıyla internet kullanma miktarı aylık ortalama 8,8 Gb olarak tespit edilmiştir. Öğrencilerin \%49’u bu miktarı yeterli görürken, \%51'i bu miktarın kendilerine yetmediğini ifade etmektedirler.

Öğrencilerin günlük internet kullanım süreleri Tablo 1'de gösterilmektedir. Öğrencilerin \%16's1 günde yaklaşık 1 saat, \%38'i günde 1-3 saat ve \%46's1 günde 3 saatten fazla internet kullanmaktadırlar. 
Tablo 1. Günlük İnternet Kullanım Süresi

\begin{tabular}{|l|c|c|}
\hline & Frekans & Yüzde (\%) \\
\hline Yaklaşık 1 saat & 18 & 16,1 \\
\hline 1-3 saat & 43 & 38,4 \\
\hline 3'ten fazla & 51 & 45,5 \\
\hline Toplam & $\mathbf{1 1 2}$ & $\mathbf{1 0 0 , 0}$ \\
\hline
\end{tabular}

Öğrenciler, esasında derste dersin amacı dışında akıllı telefon ve internet kullanımını doğru bulmamaktadırlar. Bu davranışı doğru bulan öğrencilerin oranı \%25 iken karşı çıkanların oranı $\% 75$ 'tir (Tablo 2).

Tablo 2. Derste dersin amacı dışında akıllı telefon/internet kullanımı doğru mudur?

\begin{tabular}{|l|c|c|}
\hline & Frekans & Yüzde (\%) \\
\hline Evet & 28 & 25,0 \\
\hline Hayır & 84 & 75,0 \\
\hline Toplam & $\mathbf{1 1 2}$ & $\mathbf{1 0 0 , 0}$ \\
\hline
\end{tabular}

Öğrencilerin derste siber aylaklık davranışlarının ortalamaları Tablo 3'te gösterilmektedir. Öğrencilerin siber aylaklık davranışları sıralamasının başında anlık mesajlaşma gelmektedir. İkinci sırada spor içerikli sitelerin ziyareti ve üçüncü sırada telefonla konuşma gelmektedir. En son sırada ise açık artırma sitelerine giriş yer almaktadır.

Öğrencilerin siber aylaklık düzeyi ortalaması yaklaşı 3,00 olarak bulunmuştur bu da orta düzeye denk gelmektedir.

Tablo 3. Siber Aylaklık Davranışları

\begin{tabular}{|c|c|c|c|}
\hline $\mathrm{N}=112$ & Ortalama & $\begin{array}{c}\text { Standart } \\
\text { Sapma }\end{array}$ & Değerlendirme \\
\hline Mesajlaşırım (WhatsApp vs.)* & 3,7232 & 1,22445 & Yüksek \\
\hline Spor içerikli web sitelerini ziyaret ederim. & 3,6339 & 1,36887 & Yüksek \\
\hline Telefonla konuşurum* & 3,5357 & 1,33510 & Yüksek \\
\hline Haber sitelerini ziyaret ederim. & 3,4286 & 1,24997 & Yüksek \\
\hline Müzik dinlerim (internetten veya telefona kayıtlı)* & 3,3661 & 1,27340 & Orta \\
\hline Sanal toplulukları ziyaret ederim(örn. Facebook.com) & 3,3214 & 1,20968 & Orta \\
\hline Dosya indiririm (müzik, yazılım, video gibi...). & 3,0982 & 1,28722 & Orta \\
\hline İş bulma ya da kariyer sitelerini ziyaret ederim. & 2,9821 & 1,36878 & Orta \\
\hline E-postalar1 kontrol ederim & 2,9196 & 1,26019 & Orta \\
\hline Oyun oynarım (internetten veya telefona kayıtl1)* & 2,8839 & 1,27163 & Orta \\
\hline Blog sayfalarını okurum. & 2,8750 & 1,20154 & Orta \\
\hline Bankacılık ya da finansla ilgili sayfaları ziyaret ederim. & 2,8125 & 1,27718 & Orta \\
\hline Tartışma gruplarını ziyaret ederim. (örn. Forumlar) & 2,7054 & 1,15967 & Orta \\
\hline Seyahat/tatil için yer ayırtırım. & 2,6875 & 3,11645 & Orta \\
\hline Çevrimiçi alışveriş yaparım. & 2,5714 & 1,23547 & $\mathrm{Az}$ \\
\hline Sohbet odalarına girerim. & 2,3036 & 1,29336 & $\mathrm{Az}$ \\
\hline Açık arttırma sitelerini ziyaret ederim (ör: gittigidiyor.com) & 2,2857 & 1,17350 & $\mathrm{Az}$ \\
\hline $\begin{array}{ll} & \text { Toplam } \\
\end{array}$ & $\mathbf{3 , 0 0 7 9}$ & 0,82036 & Orta \\
\hline
\end{tabular}


Siber aylaklık davranışlarının demografik özelliklere göre farklılaşma durumunu tespit etmek üzere karşılaştırmalar yapılmıştır. İki madde için cinsiyete göre ortalamaların farklı olduğu tespit edilmiştir (Tablo 4). Diğer demografik özellikler için yapılan analizlerde fark görülmediğinden bunlarla ilgili tablo düzenlenmemiştir.

Tablo 4. Cinsiyete Göre Ortalamaların Karşılaştırılması (t Testi)

\begin{tabular}{|l|r|r|r|c|c|}
\hline & Cinsiyet & Frekans & Ortalama & t & p \\
\hline \multirow{2}{*}{ Dosya indiririm (müzik, yazılım, video vb.) } & Kiz & 40 & 3,43 & \multirow{2}{*}{2,031} & \multirow{2}{*}{$0,045^{*}$} \\
\cline { 2 - 5 } & Erkek & 72 & 2,92 & \\
\hline \multirow{2}{*}{ Çevrimiçi alışveriş yaparım. } & Kız & 40 & 2,90 & \multirow{2}{*}{2,131} & \multirow{2}{*}{$0,035^{*}$} \\
\cline { 1 - 5 } & Erkek & 72 & 2,39 & \\
\hline
\end{tabular}

* $\mathrm{p}<0,05$ ise grupların ortalamaları arasında anlamlı bir fark vardır.

Demografik özelliklere göre yapılan karşılaştırmalara göre kız öğrenciler internet üzerinden daha fazla dosya (müzik, yazılım, video gibi) indirmekte ve daha fazla alışveriş yapmaktadırlar.

\section{Tartışma}

Akıllı telefonların yaygınlaşması, internet erişiminin ucuzlaması ve kolaylaşması gibi nedenlerle ders esnasında ders dişı amaçlarla bu cihazların kullanılmasının önüne geçilememektedir. İşletmelerde olduğu gibi eğitim ve öğretim alanında da siber aylaklığın olumlu ve olumsuz sonuçlarının olduğu ifade edilmektedir. Olumsuz sonuçlar olarak bu davranış yüzünden öğrencinin derse odaklanmadığı, öğrenme performansının olumsuz etkilendiği, öğrenciye verilen görev ve sorumlulukların yerine getirilmediği, sınıf yönetiminin zorlaştığ 1 vb. sıralanmaktadır. Araştırmada elde ettiğimiz bulgulara göre Beden Eğitimi ve Spor Öğretmenliği Bölümünde okuyan öğrencilerin siber aylaklık düzeyi ortadır. Karaoğlan Yılmaz vd. (2015) de üniversite öğrencilerinin siber aylaklık düzeylerini orta olarak tespit etmişlerdir.

Kalaycı (2010) yaptığı araştırma sonucunda eğitim ortamlarında en sık yapılan siber aylaklık davranışlarının e-posta kullanımı, tartışma grupları/sanal toplulukları ziyaret, dosya indirme, blog kullanımı, banka işlemleri yapma, çevrimiçi alışveriş, açık artırma sitelerini ve sohbet odalarını ziyaret, seyahat rezervasyonları yapma, kariyer sitelerini ve spor/haber sitelerini ziyaret olduğunu tespit etmiştir. Kalaycı, bu çalışmayı Bilgisayar ve Öğretim Teknolojileri Eğitimi Bölümünde okuyan öğrencilerle, 7 yıl önce yapmıştır. Geçen süre zarfında akıllı telefon ve internet kullanımı giderek yaygınlaşmıştır. Özellikle günümüzde hemen her kesim anlık mesajlaşmayı (WhatsApp gibi) hemen her ortamda ve zamanda kullanmaktadır. Diğer taraftan bizim yaptığımız araştırmanın örneklemi Beden Eğitimi ve Spor Öğretmenliği Bölümü 
öğrencilerinden oluşmaktadır. Siber aylaklık davranışlarının ilk sırasında anlık mesajlaşma ve ikinci sırada spor içerikli web sitelerinin ziyaret edilmesinin yer alması beklenebilen bir sonuçtur. Yıldırım (2016)'ın yaptığı araştırma sonuçlarına göre de üniversite öğrencileri mobil cihazları ile interneti en çok sosyal medya sitelerine girme ve haber sitelerini ziyaret etme amaciyla kullanmaktadırlar.

Ergun ve Altun (2012)'un yaptıkları çalışmada üniversite öğrencileri siber aylaklık yaptıklarını kabul etmekle beraber, bu davranışın kabul edilemez olduğunu belirtmişlerdir. Benzer sonuca Arabacı (2017) da ulaşmıştır. Kalaycı (2010)'nın çalışmasında siber aylaklık davranışını doğru bulmayanların oranı \%59 olarak tespit edilmiştir. Bizim bulgularımıza göre de öğrencilerin \%75'i derste ders dışı amaçlarla akıllı telefon ve internet kullanmanın doğru olmadığını belirtmişlerdir.

Hayıt ve Dönmez (2016) yaptıkları araştırma sonucunda erkek üniversite öğrencilerinin kız öğrencilere göre daha fazla siber aylaklık davranışı gösterdikleri sonucuna ulaşmışlardır. Benzer şekilde Keser vd. (2016)'nin yaptıkları araştırmaya göre okulöncesi öğretmenliği bölümünde okuyan erkek öğrenciler daha fazla siber aylaklık davranışı sergilemektedirler. Ancak Arabacı (2017) yaptığı çalışmada eğitim fakültesinde okuyan kız öğrencilerin haber sitelerini takip ederek siber aylaklık davranışını daha fazla gösterdikleri sonucuna ulaşmıştır. Kalaycı (2010)'nın araştırma sonuçlarına göre ise erkek öğrenciler, bireysel işler ve haber takip etme siber aylaklık davranışlarını, kız öğrencilere göre daha fazla yapmaktadır. Jackson, et al. (2001) tarafından üniversite öğrencileri üzerine yapılan araştırmaya göre kızlar erkelere göre daha fazla e-posta kullanmakta, erkekler de kızlara göre daha fazla web kullanmaktadır. Bizim araştırmamızda cinsiyete göre yaptığımız karşılaştırmalarda kız öğrencilerin erkek öğrencilere göre internet üzerinden daha fazla dosya (müzik, yazılım, video gibi) indirdiği ve daha fazla alışveriş yaptığı sonucuna ulaşılmıştır. Ancak siber aylaklık genel düzeyi bakımından kız ve erkek öğrenciler arasında bir fark tespit edilmemiştir.

\section{Sonuç-Öneriler}

Günümüz teknolojisinin sunduğu imkânlar siber aylaklık davranışlarının gösterilmesini kaçınılmaz hale getirmektedir. Araştırma verilerinin elde edildiği öğrencilerin siber aylaklık seviyeleri orta olup öğrenciler, esasında bu davranışları tasvip etmemektedir. Siber aylaklığ1 ortadan kaldırmak mümkün olmadığından en azından bunun kontrol altına alınması gerekmektedir. Bu bağlamda sınıf kurallarının açıkça ortaya konulması, dersin daha çekici hale getirilmesi, öğrencilere sorumluluk verilmesi, dersin öneminin öğrencilerce anlaşılmasının 
sağlanması, öğrencilerin zaman yönetimi becerilerinin geliştirilmesi ve bireysel etkinliklerle yer vererek derse zaman zaman ara verilmesi gibi tedbirler siber aylaklık davranışlarını azaltabilir.

\section{Kaynakça}

Agarwal, R. and Karahanna, E. (2000). Time flies when you're having fun: Cognitive absorption and beliefs about information technology usage. MIS Quarterly. 24 (4): 665694.

Anandarajan, M., Simmers, C. and Igbaria, M. (2000). An exploratory investigation of the antecedents and impact of internet usage: An individual perspective. Behavior and Information Technology. 19 (1): 69-85.

Arabacı, İ.B. (2017). Investigation faculty of education students' cyberloafing behaviors in terms of various variables. TOJET: The Turkish Online Journal of Educational Technology. 16 (1): 72-82.

Blanchard, A. and Henle, C. (2008). Correlates of Different Forms of Cyberloafing: The Role of Norms and External Locus of Control. Computers in Human Behavior, 24(3): 10671084.

Çınar, O. (2010). Okul müdürlerinin iletişim sürecindeki etkililiği. Dumlupınar Üniversitesi Sosyal Bilimler Dergisi. 26 (2): 267-276.

Ergün, E. ve Altun, A. (2012). Öğrenci gözüyle siber aylaklık ve nedenleri. Ĕ̆gitim Teknolojisi: Kuram ve Uygulama. 2 (1): 36-53.

Hayıt, T. ve Dönmez, O. (2016). Üniversite öğrencilerinin siber aylaklık profilleriyle bilişsel kapılma düzeyleri arasındaki ilişkinin incelenmesi. Ĕ̆itim ve Öğretim Araştırmaları Dergisi. 5: 146-150.

Jackson, L.A., Ervin, K.S., Gardner, P.D. and Schmitt, N. (2001). Gender and the internet: Women communicating and men searching. Sex Roles, 44 (5/6): 363-379.

Jones, S. (Ed.). (2002). Encyclopedia of New Media: An Essential Reference to Communication and Technology. Sage Publications.

Kalaycı, E. (2010). Üniversite Öğrencilerinin Siber Aylaklık Davranışları ile Öz Düzenleme Stratejileri Arasındaki İlişkinin İncelenmesi. Hacettepe Üniversitesi Fen Bilimleri Enstitüsü. Yayınlanmamış Yüksek Lisans Tezi. 
Karaoğlan Yılmaz, F.G., Yılmaz, R., Öztürk, H.T., Sezer, B. and Karademir, T. (2015). Cyberloafing as a barrier to the successful integration of information and communication Technologies into teaching and learning environments. Computers in Human Behavior. 45: 290-298.

Karasar, N. (2000). Bilimsel Araştırma Yöntemi, Nobel Yayıncılık: Ankara.

Keser, H., Kavuk, M. and Numanoglu, G. (2016). The relationship between cyberloafing and internet addiction. Cypriot Journal of Educational Science. 11 (1): 37-42.

Knight, R.M. (2017). Academic Cyberloafing: A Study of Perceptual and Behavioral Differences on In-Class Cyberloafing among Undergraduate Students. East Carolina University. Master Thesis of Arts in Psychology.

Koçak Usluel, Y. ve Kurt Vural, F. (2009). Bilişsel kapılma ölçeğinin Türkçeye uyarlama çalışması. Ankara Üniversitesi Ĕgitim Bilimleri Fakültesi Dergisi. 42 (2): 77-92.

Kurt, M. (2011). Siber aylaklık davranışlarının karşılaştırmalı olarak incelenmesi. 5th International Computer and Instructional Technologies Symposium. 22-24 September, Firat University, Elazı $\breve{g} /$ Turkey, 935-941.

Lim, V.K. (2002). The IT way of loafing on the job: Cyberloafing, neutralizing and organizational justice. Journal of Organizational Behavior. 23 (5): 675-694.

Örücü, E. ve Yıldız, H. (2014), İşyerinde kişisel internet ve teknoloji kullanımı: Sanal kaytarma. Ege Akademik Bakış. 14 (1): 99-114.

Ugrin, J.C., Pearson, J.M. and Odom, M.D. (2007). Profiling cyber-slackers in the workplace: Demographic, cultural and workplace factors. Journal of Internet Commerce. 6 (3): 7589.

Weatherbee, T.G. and Kelloway, E.K. (2006). A case of cyberdeviancy: Cyberaaggression in the workplace. In E. K. Kelloway, J. Barling, and J. J. Hurrell (Eds.). Handbook of Workplace Violence. (pp. 445-487). Thousand Oaks, CA: Sage Publications, Inc.

Yıldırım, E. (2016). Sınıf Öğretmenleri Adaylarının Siber Aylaklık Sorununa İlişkin Durum Analizi. Fırat Üniversitesi Eğitim Bilimleri Enstitüsü. Yayınlanmamış Yüksek Lisans Tezi. 